\title{
$\operatorname{arCOS} D E S I G N$
}

\section{Por práticas relacionais no design}

Ana Julia Melo Almeida (FAU-USP, Brasil)

ajuliamelo@usp.br

Faculdade de Arquitetura e Urbanismo da Universidade de São Paulo Rua do Lago, 876 - Butantã, São Paulo

\section{Bruna Ferreira Montuori (FAU-USP, Brasil)}

brunamontuori@usp.br

Faculdade de Arquitetura e Urbanismo da Universidade de São Paulo Rua do Lago, 876 - Butantã, São Paulo

Viviane Mattos Nicoletti (FAU-USP, Brasil)

viviane.nicoletti@usp.br

Faculdade de Arquitetura e Urbanismo da Universidade de São Paulo Rua do Lago, 876 - Butantã, São Paulo

\section{Maria Cecilia Loschiavo dos Santos (FAU-USP, Brasil)}

closchia@usp.br

Faculdade de Arquitetura e Urbanismo da Universidade de São Paulo Rua do Lago, 876 - Butantã, São Paulo 


\title{
Por práticas relacionais no design
}

Resumo: O presente artigo busca construir uma noção de design relacional que articula o campo do design e elucida práticas que reconhecem as hierarquias e as desigualdades existentes. O objetivo é repensar a postura dos profissionais e refletir maneiras de reposicionar o lugar de fala dos atores envolvidos considerando-os como participantes ativos. Trata-se de um alargamento teórico para a prática de design, ao considerar outras maneiras de pensar e fazer design. Evidencia-se a troca com outros campos do conhecimento, como a antropologia, filosofia, sociologia e a arte, visando a fomentar a multidisciplinaridade a partir de outras capacidades de ação, incluindo a cooperação, o aprendizado e a reciprocidade.

Palavras-chave: Design Relacional, Cooperação, Correspondência, Multidisciplinaridade.

\section{Towards relational practices in design}

\begin{abstract}
The following article seeks to build a relational notion of design, which articulates the field of design and elucidates practices that acknowledge existing hierarchies and inequalities. Our goal is to rethink the professional's posture and to reflect upon repositioning the voices of involved actors as considering them active participants. It is about a theoretical enlargement to the design practice when considering other forms of thinking and doing design. It is denoted the exchange with other fields of knowledge, such as anthropology, philosophy, sociology and art, aiming to foster multidisciplinarity by means of other capabilities of action, including cooperation, learning and reciprocity.
\end{abstract}

Keywords: Relational Design, Cooperation, Correspondence, Multidisciplinarity. 


\section{Introdução}

Este artigo tem como intuito apresentar e debater a ideia de práticas relacionais no campo do design, a fim de contribuir com a perspectiva de que o design pode atuar como um mediador de processos autóctones aqueles que reconhecem soluções encontradas no próprio território e que, a partir delas, promovem autonomia, considerando os diferentes grupos sociais, evitando imposições e padronizações. Em um contexto de evidentes crises sociais, políticas e econômicas, pesquisadores e profissionais da área têm buscado caminhos possíveis para outras formas de fazer design, além da tradicional percepção do campo como prática propositiva, no qual encontrar soluções é a máxima projetual.

Consideramos que a visão hegemônica ${ }^{1}$ do campo não compreende a complexidade dos componentes da vida, por isso, reconhecemos os contextos urgentes e conflituosos para pensar e praticar o design nos tempos atuais. A pesquisadora Donna Haraway (2016) considera a importância de um pensamento voltado para a multiplicidade de atores e trocas entre espécies superando a era do antropoceno ${ }^{2}$ direcionada unicamente para a humanidade. A autora (Ibid., p.37) nos orienta para as urgências e suas temporalidades e a importância de pensarmos os problemas e contá-los por meio de diferentes histórias ${ }^{3}$.

Nesse sentido, a teórica indiana pós-colonialista Gayatri Spivak (2010) denuncia que a tradicional visão da história tende a monopolizar a percepção dos fatos históricos, ancorada em uma narrativa pautada em cernes hegemônicos, que privilegia a manutenção da ordem vigente, como coloca em suas palavras:

Não se trata de uma descrição de 'como as coisas realmente eram' ou de privilegiar a narrativa da história como imperialismo como a melhor versão da história. Trata-se, ao

\footnotetext{
${ }^{1}$ Como visão hegemônica do campo compreendemos práticas padronizadas e generalistas, tal como aquelas exclusivamente industriais e para produção consumista de massa - ancoradas no pensamento moderno; o design para inovação social que parte de visões europeias para pensar contextos complexos, que muitas vezes estão fora do Norte Global; o design thinking e sua abordagem direcionada apenas para solucionar problemas dos ditos usuários ao invés de integrá-los nos projetos de design como atores propositivos; entre outras.

${ }^{2}$ Para a autora, o antropoceno representa tempos de urgência de todas as espécies: das grandes mortes em massa e extinção, de desastres acelerados, a falta de capacidade de desenvolver uma habilidade responsiva, em outras palavras, tempos que aceleram a catástrofe a frente (Cf. HARAWAY, 2016, p.35).

${ }^{3}$ Haraway sugere esta concepção a partir da seguinte passagem: "I name these things urgencies rather than emergencies because the latter word connotes something approaching apocalypse and its mythologies. Urgencies have other temporalities, and these times are ours. These are the times we must think; these are the times of urgencies that need stories" (HARAWAY, 2016, p.37).
} 
contrário, de oferecer um relato de como uma explicação e uma narrativa da realidade foram estabelecidas como normativas (SPIVAK, 2010, p.48).

Ao considerar as diferentes narrativas presentes nos contextos plurais que encontramos no território brasileiro - marcado por desigualdades e múltiplas identidades em constante transformação compreendemos a necessidade de aproximação do campo do design com outras áreas de conhecimento, especialmente das ciências sociais e humanas, para propiciar práticas que reconheçam os conflitos e as diferenças existentes, ampliando a capacidade de escuta e diálogo. Tomaremos emprestado debates destas áreas do conhecimento, em reflexão e por espelhamento para pensar questões de design.

Neste intuito, buscamos direcionar questionamentos a fim de repensar o papel das e dos profissionais, seus posicionamentos, posturas e as suas formas de se relacionar com outros modos de fazer e viver em sociedade. Trata-se de uma perspectiva mais ampla, não ancorada apenas em concepções formais, mas que envolve também contextos não institucionalizados e informais, relacionando diferentes saberes e espaços. Nosso objetivo é reconhecer na prática do design as hierarquias e desigualdades existentes e, a partir destas, debater um reposicionamento dos atores envolvidos nessas relações, por meio da diversidade de conhecimentos, culturas e fazeres.

O antropólogo Eduardo Viveiros de Castro (2004) apresenta a noção do perspectivismo, que é composta por diferentes tipos de agências subjetivas, humanas e não humanas, dotadas dos mesmos conjuntos de capacidades, gerando diferentes visões a partir dos observadores. Outra noção levantada pelo autor é a equivocação controlada, em que os equívocos são resultado de um estranhamento entre os atores envolvidos pesquisador e interlocutor -, na qual ocorre uma negociação de identidades e uma comunicação pelas diferenças:

O equívoco não é aquele que impede a relação, mas o que a encontra e a impulsiona: a diferença na perspectiva. Traduzir é presumir que a equivocação sempre existe; é comunicar pelas diferenças, em vez de silenciar o Outro presumindo uma univocidade - a similaridade essencial - entre o que o Outro e Nós estamos dizendo (VIVEIROS DE CASTRO, 2004, p.8)4.

\footnotetext{
${ }^{4}$ No original: "The equivocation is not that which impedes the relation, but that which founds and impels it: a difference in perspective. To translate is to presume that an equivocation always exists; it is to communicate by differences, instead of silencing the Other by presuming a univocality - the essential similarity - between what the Other and We are saying".
} 
A antropóloga Marilyn Strathern (1991) advoga por um pensamento capaz de conjugar mundos diversos, estudando as relações com as relações, por meio de conexões parciais e não universais. Para a pesquisadora, pensar conexões parciais equivale a colocar os diferentes elementos em relação e evidenciá-los, ainda que em risco. Neste sentido, Haraway (2016, p.34), por meio do pensamento de Strathern, apresenta uma ecologia de práticas pautada no conhecimento e no fazer coletivo, aceitando e evidenciando os conflitos existentes.

É possível notar, em práticas contemporâneas de projeto, relações objetivas que posicionam a solução e o anseio por resultados inovadores como finalidade principal de suas atividades. Notamos que, por vezes, há a ausência de um pensamento de design capaz de aproximar diferentes contextos e engajar suas práticas em situações cotidianas de habitantes de espaços formais e informais, públicos e privados.

Sobre os contextos de severa vulnerabilidade, a pesquisadora Maria Cecilia Loschiavo dos Santos (2000) afirma que existe um senso de adaptação à precariedade, no qual estão presentes práticas de design espontâneo. Há um sentido efetivo de improvisação, por meio do qual estas populações, que vivem nesses contextos, se adaptam às condições que desafiam sua sobrevivência cotidiana. Para a autora, o design espontâneo é uma prática criativa de encontrar soluções para resolver problemas concretos, em contextos de grave falta de recursos ${ }^{5}$ (SANTOS, 2000, p.2).

O arquiteto indiano Rahul Mehrotra (1998), ao lidar com contextos de severa vulnerabilidade social em Mumbai, na Índia, aponta para a desconexão da prática de projeto em um panorama mais amplo e engajado:

Arquitetos e designers trabalhando em tais contextos lidam agora com uma enorme gama de questões sociais, culturais e econômicas e problemas que estão usualmente alienados as suas profissões. Na práxis convencional, o profissional não se engaja neste panorama mais amplo de questões mas escolhe operar com as especificidades de um lugar, em um processo que muitas vezes torna-se desconectado de um contexto amplo da prática (MEHROTRA, 1998, p.7).

Tratando-se de gerações de profissionais do design formados com bases metodológicas apoiadas em conceitos operadores do design thinking e da inovação em design, além das tradicionais bases modernistas ulmiana e bauhausiana, as estratégias de atuação em congruência com questões sociais urgentes e complexas nem sempre são aprofundadas e tratadas com maior atenção, como realizado em outros campos das ciências sociais. Em conformidade com esta proposta, a pesquisadora em design Elizabeth

${ }^{5}$ No original: "Spontaneous design is a creative practice of finding applicable work solutions to solve concrete problems, in contexts of severe lack of resources". 
Tunstall (2013) contrapõe esta visão e advoga por um design decolonizado engajado em práticas culturais, que reconheça e possibilite voz e espaço a conhecimentos de outros povos e culturas. Tunstall (Ibid., p.238, tradução nossa) propõe uma "metodologia decolonizada" que, por meio de design anthropology, reconhece um "sistema de métodos, princípios e regras livres dos preconceitos dos últimos cinco séculos de colonização e imperialismo"6, e assim contribui para a autodefinição e autodeterminação daqueles anteriormente colonizados.

Embora tais processos de decolonização sejam lentos e tenham uma alta oscilação, o campo do design vem questionando o aspecto colonialista da profissão nas últimas décadas, e apresenta outras formas nas quais profissionais podem se relacionar com práticas projetuais e processuais. Vale ressaltar o pensamento das pesquisadoras Lauren Weinstein e Cinnamon Janzer (2015), com relação ao viés social do campo, ao endereçar que ao passo que os designers entram na esfera social - e mudam de projetar objetos para projetar mudanças sociais - a necessidade de uma prática social ética deve ser reconhecida e desenvolvida. O campo do design deve adotar práticas novas e mais adequadas e modificar métodos inadequados para a concepção de situações. O design precisa reorientar sua filosofia teórica para longe da tradição de prioridades direcionadas ao ser humano, que tendem a ser dirigidas aos objetos, e mudar para novas prioridades centradas na situação - concentradas no social (WEINSTEIN \& JANZER, 2015, p.328).

A partir de tais constatações e do foco situacional, apresentaremos neste artigo uma perspectiva de como o design pode se relacionar com outros contextos - em especial os não institucionalizados e informais - e seus diferentes atores. Procuraremos pensar em abordagens mais justas que considerem as diferenças existentes como possibilidades de aprendizados mútuos; trocas recíprocas que evidenciem as diferentes formas de fazer e pensar; e caminhos para cooperação que reconheçam as desigualdades, evitando perspectivas assistencialistas.

Donna Haraway (2016, p.27-28) propõe um pensamento para atuarmos de forma coletiva dentro de situações de conflito, reconhecendo os problemas existentes e permanecendo neles. Não se trata de uma reconciliação ou uma restauração, mas sim das possibilidades de recuperações parciais no estar juntos - na língua inglesa, "getting on together". Assim, podemos nos valer de um posicionamento menos

\footnotetext{
${ }^{6}$ No original: "I am proposing design anthropology as a methodology rather than a method, because what is at stake for me are the principles and rules for regulating the disciplines of design and anthropology to avoid neocolonization and imperialism".
} 
defensivo e a partir de abordagens abertas que busquem relações mais justas.

Acreditamos ser fundamentais práticas de projeto que estejam apoiadas no complexo contexto brasileiro, capazes de refletir sobre as relações sociais, culturais e econômicas locais, visto que o nosso território é permeado por conhecimentos e fazeres que estão situados em contextos de informalidade. O distanciamento existente entre atores do campo e outros atores sociais e seus respectivos contextos requer outras formas de se relacionar, que propiciem trocas de aprendizado e correspondência, como abordado por Tim Ingold (2016). Em razão disso, ao discutir a ideia de relacional estabelecemos ponte com abordagens de design: que agregam aspectos transicionais, como aqueles discutidos pelo antropólogo Arturo Escobar (2017); que conjugam sua prática com outros campos, tal como a antropologia, por meio do design anthropology (Gunn et al, 2013; Gunn; Donovan, 2012; Smith et al, 2016); que envolvem outros atores e colocam designers e pesquisadores como coatores em processos e projetos, apoiados aqui pelo codesign; e ainda outras, que evidenciam a subjetividade intrínseca às culturas humanas e suas maneiras de se relacionar e viver.

Neste sentido, o artigo divide-se em três partes que visam aproximar os aspectos relacionais às práticas de design, elucidando outros modos de ação, interação e troca mútua que reconheçam o caráter responsivo da prática, ao invés de pousar sobre os profissionais a responsabilidade total imbuída em olhares fraternalistas (GAMmAN \& THORPE, 2011). As partes do artigo envolvem (1) uma tentativa de construção da noção de relacional; (2) a atribuição dessa noção às práticas de design nas conjunturas social, cultural e política vigentes; e, por fim, (3) as práticas relacionais no design na América Latina, englobando o contexto plural brasileiro, em suas perspectivas social e política.

\section{Ensaio sobre a noção de relacional}

Antes de abordarmos a noção de relacional nas práticas de design, traçamos um percurso amparado nos campos da antropologia, sociologia e filosofia da arte, a fim de compreendermos termos e conceitos essenciais para o desenvolvimento teórico do termo relacional. Buscamos, por meio deste aprofundamento, levantar pontos e desdobramentos que contribuam para esta construção e auxiliem a endereçar esta noção à prática propositiva inerente às habilidades humanas.

No campo da antropologia, Marcel Mauss (2017) parte de materiais etnográficos de povos da Polinésia, Melanésia e indígenas da América do Norte durante as primeiras décadas do século XX para refletir sobre as relações de troca entre atores sociais e as hierarquias entre culturas e povos. 
Neste processo, o antropólogo investigou e problematizou o termo "primitivo" associado a essas populações, que muitas vezes foram classificadas como sociedades inferiores. A partir de suas análises, Mauss (Id.) relatou uma complexa estrutura social e econômica de prestações e contraprestações, que não eram mediadas por trocas monetárias e, portanto, adquiriram em meio aos que se inseriram no contexto ocidental uma condição de inferioridade em relação às que fundamentaram suas trocas com base monetária. Ao reconhecer as diferenças presentes nas práticas sociais de tais sociedades, o autor pôde aprofundar o conhecimento sistematizado sobre as trocas existentes como propulsoras das relações sociais, possibilitando uma expansão de perspectivas e olhares.

As trocas ou dádivas, recuperadas por meio do trabalho de Mauss, estabelecem historicamente as formas de se relacionar - especialmente em sua visão economicista - e, embora de longa data, são contínuas e presentes em nosso cotidiano, do simbólico ao capitalismo em trocas subjetivas, incluindo circunstâncias como o favor e a esmola. As formas de trocar, o dar, o receber e o retribuir, são ações dialéticas e interdependentes que moldam o modo como nos relacionamos com os outros. Em consonância à noção de relacional que buscamos inferir, Caroline Gatt e Tim Ingold (2013), por meio do trabalho de Mauss, situam as dádivas como instrumento importante para a compreensão das trocas:

Dádivas (...) não viajam para frente e para trás, mas ao longo, passando de mãos em mãos onde as linhas de vida se sobrepõem e se envolvem umas às outras, como em um relé. Como uma linha proferida na conversa, uma transação particular pega o fluxo da vida social e transmite-a para a frente, e seu significado só pode ser compreendido no contexto de uma história de trocas anteriores de que é apenas um momento singular (GATT \& INGOLD, 2013, p.142).

Ao expor o sistema complexo das trocas, Mauss (2003) traz o conceito de equiparidade cultural. Sobre isso, o antropólogo Roy Wagner (2010, 29) esclarece que toda cultura pode ser entendida como uma manifestação específica e presume que cada uma delas é equivalente a qualquer outra, fenômeno que denomina de "relatividade cultural". Não queremos inferir que a relatividade cultural é relacional, mas sim que ela pode auxiliar na construção do entendimento do relacional. Em razão disso, situamos como a relatividade cultural pode auxiliar na construção do entendimento de relacional.

Ainda sob a perspectiva da relatividade cultural, Wagner (2010, p.29) escreve que "a compreensão de uma outra cultura envolve a relação entre duas variedades do fenômeno humano; ela visa a criação de uma relação intelectual entre elas, uma compreensão que inclua ambas". Neste sentido, ao pensarmos a cultura por meio de uma objetividade relativa, 
podemos repensar também as práticas de design de maneira que elas permitam compreender e incluir outros espaços de fazer. O autor (Ibid., p.28) evidencia que o caminho para a objetividade relativa é buscar "as maneiras pelas quais nossa cultura nos permite compreender uma outra e as limitações que isso impõe”.

Ao falar sobre a produção de sentido no trabalho do antropólogo, Viveiros de Castro (2002) aponta que o conhecimento antropológico implica também em relações sociais, "pois é o efeito das relações que constituem reciprocamente o sujeito que conhece e o sujeito que ele conhece, e a causa de uma transformação (toda relação é uma transformação) na constituição relacional de ambos" (Ibid., p.113-114). O autor ainda esclarece que todo conhecimento antropológico é mediado culturalmente; nessa direção, a igualdade entre os conhecimentos não implica uma igualdade de direitos, mas uma equivalência no plano dos conhecimentos.

Nessa perspectiva, procuraremos refletir sobre o campo do design de forma análoga à de Viveiros de Castro. Segundo o autor, "se há algo que cabe de direito à antropologia, não é certamente a tarefa de explicar o mundo de outrem, mas a de multiplicar nosso mundo" (Ibid., p.132). Direcionado ao design, não caberia a este campo a tarefa de solucionar os problemas dos mundos sociais, mas, sim, de multiplicar, experimentar e estabelecer práticas de correspondências com outras pessoas, em outros contextos, que também atuam na produção de nossa cultura material.

Ao buscar maneiras pelas quais as múltiplas culturas de design - do fazer e do projetar - nos permitiriam compreender outros espaços, situados fora do contexto formal do campo, refletimos sobre caminhos possíveis que levam a práticas propositivas, mas que conseguem relacionar os diversos conhecimentos, atores e contextos, sem deixar de enxergar as limitações ao olhar e compreender tais espaços. Tais trajetos, apoiados no viés relacional aqui proposto, são conformados na capacidade de cooperação do design em rituais vivos, na qual o equilíbrio depende das trocas, como elucidado pelo sociólogo Richard Sennett (2013).

Os rituais, por sua vez, quando memorizados, "possibilitam que as coalizões com parceiros fortes e fracos trabalhem juntas para seu benefício comum", dando "forma às trocas informais de ganha-ganha". Já a cooperação está na habilidade humana de somar ações em rituais cotidianos, na qual a comunidade desvela a sua própria vocação, oposta à lógica do individualismo característico da sociedade capitalista de consumo. Para o autor (Ibid., p.5, tradução nossa), a cooperação pode ser definida "como um intercâmbio, no qual os participantes se beneficiam da sua reunião".

Ao falar sobre práticas no campo da arte, Rancière (2002) escreve que a emancipação intelectual equivale a pensar em uma condição de 
igualdade das inteligências: não significa dizer que todas as manifestações da inteligência presentes nas produções humanas tenham igual valor, mas sim compreendê-las dentro de uma espaço de igualdade das inteligências em todas as suas manifestações. Para o autor, igualdade e inteligência são termos sinônimos e se fazem presentes na capacidade intelectual de cada indivíduo. Essa perspectiva se apresenta como um caminho possível para pensar em uma organização coletiva, que seja mais próxima do que o teórico denomina uma "comunidade dos iguais". O autor não extingue as diferenças nessa comunidade, mas as torna possíveis em uma convivência expandida, em uma partilha e uma emancipação dessas inteligências. Não é uma questão, ainda para o autor, de borrar as distinções entre as inteligências, mas de assumi-las com equidade em suas diferenças.

O autor (2002) aponta ainda que não há dois tipos de inteligências separadas por um abismo, ou melhor: que a distância existente entre as diversas inteligências não deveria ser transformada em abismo. A distância não é um mal em si, que precisaria ser abolido, mas uma condição presente na comunicação humana. Em nossa reflexão, compreendemos a importância do pensamento de Rancière ao propor práticas mais horizontais na relação entre os conhecimentos e os fazeres humanos. Portanto, ao mesmo tempo em que é preciso reconhecer os contextos desiguais presentes nas práticas de design, é fundamental considerar também as inteligências que estão presentes nas ações humanas, em um conflito democrático entre diferentes e desiguais.

A partir da noção de relacional, buscamos compreender essa distância como ponte e ligações possíveis entre os diversos fazedores de nossa cultura material, designers e não-designers. Indagamos como as práticas de design poderiam estabelecer espaços de trocas mútuas, reconhecendo o lugar em que cada fazedor se encontra e considerando as suas particularidades.

Finalmente, na tentativa de construção de uma noção de relacional, acreditamos que esta esteja imersa na capacidade de apreensão dos rituais cotidianos daquele com quem se trabalha junto; na habilidade em promover emancipação intelectual, por meio do reconhecimento do lugar de fala e na igualdade de conhecimentos e diferentes sistemas de valores; nos modos de cooperação e aprendizado mútuo; e nas trocas contínuas que visam seu equilíbrio por meio da alteridade e reciprocidade. Para tanto, compreendemos a ideia de relacional como uma possível lógica e não como uma norma. O termo não possui uma única definição, mas um arranjo de perspectivas plurais e situacionais capazes de multiplicar as maneiras de refletir sobre as nossas ações e relações vivenciadas pelo design. Por este caminho, entraremos a seguir em como entendemos que esta noção pode ser aplicada diretamente ao design e suas práticas. 


\section{Atribuição da noção de relacional ao design}

$\mathrm{Na}$ busca pelos pontos levantados, ambicionamos traçar um panorama em que a prática do design é relacional, e para tanto tratamos alguns conceitos que elucidam uma prática alinhada com esta perspectiva. Entre alguns vieses abordados, nos apoiamos no texto 'O Prometeu Cauteloso', do filósofo e antropólogo Bruno Latour (2008), em que direciona aos designers a necessária revisão do campo e de suas práticas.

O autor (Idem) refuta a visão humanista, que está apenas preocupada com os seres humanos, tratando os demais atores como "mera materialidade ou fria objetividade", logo lidando com estes como fatos acabados. Desta forma, o autor abraça a importância de nos dirigirmos a 'questões de interesse' - do inglês 'matters of concern' - ao invés de nos limitarmos às 'questões de fato' - do inglês matters of fact' -, tratando com igualdade objetos humanos e não humanos - objetos e sistemas - em uma relação de cuidado entre todas as partes.

Com esta mudança de atitude, praticantes se libertariam de antigos estilos hegemônicos do moderno que naturalizam e segregam os objetos não-humanos dos humanos, isto é, as coisas das pessoas. Por este caminho, o autor sugere uma prática de design que promove o desenho coletivo, em que as questões de interesse são colocadas em discussão a todo momento, propiciando a expressão e a representação de todos os atores e suas opiniões em um projeto ou processo de colaboração, evidenciando uma prática de design não linear, objetificada e reificada (Ibid., p.13).

De outro modo, o antropólogo britânico Tim Ingold (2012) encara as relações sociais como uma malha de fios, na qual os fios são coisas e pessoas e os seus nós são encontros entre eles. Para o autor, tais encontros acontecem por meio de reciprocidade entre as partes, processo que ele denomina de "práticas de correspondência". Aqui, refletimos estas práticas para o design e apoiamos a noção de relacional na ideia de correspondência como possível caminho de ação. Na perspectiva de Ingold (2016) as correspondências representam "o modo de se relacionar de um ser que habita no hábito, cuja agência é sempre emergente e cuja postura é atencional". Ao apresentar o tema sobre a transmissão de representações, o autor (2001) aborda a relevância de se construir uma "educação da atenção", dialogando diretamente com a postura precisa para a correspondência.

Com base no pensamento de Ingold (2016), assumimos design como uma prática de correspondência, na qual os profissionais possam se deixar levar pelo fazer local a partir da apreensão do seu fluxo de vida, rituais e improvisações cotidianas. Para o autor (Idem), a correspondência é 
uma forma de se relacionar com o outro, ao adotar uma postura de atenção, baseada na vivência e nos hábitos do outro em que o agenciamento emerge de dentro, potencializando o que já está em evidência. Assim, na língua inglesa, o termo "doing undergoing" é fazer e seguir o outro, se permitir levar com o outro, por nós interpretada como 'deixar-se submeter', constituindose como uma importante atitude para que a correspondência ocorra, e a prática se constitua verdadeiramente relacional.

Nesta direção, a correspondência dialoga com a abordagem de design anthropology, que conjuga práticas dos campos do design e da antropologia (GUNN \& DONOVAN, 2012, p.1-16) almejando processos abertos que permitem a criatividade do design baseada "na capacidade dos habitantes de responder com precisão às circunstâncias de mudança contínuas em suas vidas" (GATT \& INGOLD, 2013, p.145). Embora nem sempre seja possível uma prática relacional baseada em tais formas de pensar, ao abrirmos a prática para outros atores, de modo que ela continue viva em suas mãos mesmo sem a presença de um designer auxiliador, rompemos com a sua atitude tradicional de solucionador de problemas para um emancipador de processos (DI SALVO, 2009, p.60).

Assim reconhecemos uma prática de design que envolve diferentes atores sociais, o que requer uma compreensão de sua dimensão política. A pesquisadora do design Ramia Mazé (2014) ressalta a importância de pensarmos o design nessa perspectiva e como esta abordagem implica em uma expansão dos papéis do design e também de sua teoria atualmente. Para a autora, tais questões apontam para uma dimensão micropolítica de reproduzir e reorganizar as relações sociais cotidianas por meio das práticas de design:

Política é sempre sobre a ordem vigente, a reprodução ou a desconstrução da hegemonia, que está sempre em relação a uma ordem potencialmente contra-hegemônica. O design sempre está fazendo política neste sentido - sempre atuando no mundo para (re)produzir a ordem socioespacial ou para romper uma determinada ordem (MAZÉ, 2014, p.562, tradução nossa $)^{7}$.

A partir desta compreensão que envolve várias relações e vários atores, percebemos a importância de posicionarmos o design em uma perspectiva mais ampla de fatores econômicos e políticos vigentes. Desta forma, compreendemos as diferenças históricas, sociais e culturais em que a prática relacional deve considerar ao atuar em determinados contextos. Em

\footnotetext{
${ }^{7}$ No original: "Politics is always about the establishment, the reproduction, or the deconstruction of a hegemony, one that is always in relation to a potentially counterhegemonic order. Design is always doing politics in the sense - it is always acting in the world to (re)produce social-spatial order or to rupture a particular order".
} 
razão disso, nos debruçamos sobre uma prática relacional no âmbito latinoamericano, ainda pouco difundido e compartilhado em relação às tradicionais referências do Norte Global, a fim de reunir um arcabouço teórico que se delineia a partir das questões de interesse do Sul Global.

\section{A prática relacional no design na América Latina}

Enquanto o Norte Global busca por caminhos experimentais para desafiar questões sociopolíticas relacionadas a futuros mais sustentáveis, o Sul Global ainda lida com conflitos sociais de moradia, compartilhamento de espaços públicos, exploração da terra e autonomia social. Neste contexto, mais especificamente no Brasil, desigualdade e questões sociais complexas são problemas cotidianos. Os "problemas contraditórios" (do inglês wicked problems), como discutido por Rittel e Webber (1973) e depois trazidos ao design por Richard Buchanan (1992), ainda prevalecem e colocam desafios também aos designers. Cinquenta anos atrás, o designer Aloisio Magalhães acreditava que os mesmos problemas seriam resolvidos pela industrialização em coordenação com projetos de design (MAGALHÃes in SOUZA LEITE, 2014). Na verdade, o cenário que enfrentamos hoje é que muitos profissionais saem a campo para trabalhar com problemas diferentes de sua própria realidade e com outras demandas da vida cotidiana, mas sem preparação para se envolver na esfera pública. Envolver-se na esfera pública requer uma compreensão do distanciamento existente entre esses contextos desiguais e também o reconhecimento dos diferentes atores e relações que compõem esses espaços para que uma prática relacional seja possível.

Mais uma vez, a ideia de relacional, aqui, visa desenvolver um entendimento sobre a multiplicidade de pontos de vista no que se refere a rituais sociais e interações diárias. Estes engajam ferramentas que desvelam culturas tradicionais de saberes vernaculares e suas estratégias socioeconômicas, como descritas pelo colombiano Escobar $(2007,2016)$ e o economista equatoriano Alberto Acosta (2016). O último apresenta o Bem Viver como uma proposta de sociedade construída coletivamente nos "caldeirões de longos processos históricos, culturais e sociais" (ACOSTA, 2016, p.23) especialmente no mundo indígena dos países andinos e amazônicos, apontando que estas são civilizações vivas que enfrentam a modernidade colonial. O Bem Viver supera a tradicional visão de desenvolvimento, introduzindo valores pautados na reciprocidade e na solidariedade para "construir relações de produção, de intercâmbio e de cooperação que propiciem suficiência” (Ibid., p.27).

$\mathrm{O}$ autor questiona o real efeito democratizante dos avanços tecnológicos, já que muitas das novas técnicas são colocadas de maneira a perpetuar as desigualdades sociais. Segundo o autor, isso acontece porque a 
energia criadora direciona-se para atender interesses de uma elite política e financeira. Por isso, é necessário que um esforço multidisciplinar seja direcionado a solucionar os grandes problemas globais, que giram em torno de uma nova economia. Entre os principais pontos: a solidariedade, a sustentabilidade, a reciprocidade, a complementaridade, a responsabilidade, a integralidade, a suficiência, a diversidade cultural e a identidade, as equidades e a democracia (Ibid., p.163-164). Sob essa perspectiva colaborativa, considerando inclusive os saberes ancestrais e tradicionais, aqueles que não circulam por espaços institucionalizados, é que entendemos o papel relacional do design, ao se portar como meio para viabilizar as trocas entre os atores de um novo modo de vida colaborativo.

O modo de vida colaborativo se opõe ao difundido conceito de progresso. Escobar (2007) apresenta uma reflexão sobre o discurso desenvolvimentista, originado no colonialismo, que é pautado num conceito de progresso do qual tem sido imposto a grande parte dos países da Ásia, África e América Latina, por meio de um encadeamento de regimes de supressão das culturas locais e do reconhecimento identitário. Este processo resultou em um cenário de violência, que por muitas vezes imobiliza uma possível articulação. Essa conjuntura permitiria a formação de um regime de representação que propõe um novo modo de vida, visando a uma formação alternativa de desenvolvimento para a sociedade. Por isso, para subverter o conceito desenvolvimentista imposto, seria necessário romper com o discurso vigente, abrindo fissuras que permitem a construção do debate para o desenvolvimento pautado na promoção da justiça social, da autonomia local e do viver colaborativo.

Esse conceito de desenvolvimento também é tratado por Escobar (2016, p.213), quando apresenta o que denomina de design autônomo, ou seja, a prática de design que é sensível e receptiva às questões apresentadas pelo coletivo. O autor (Idem) considera um design para autonomia, que tem como estrutura básica a reafirmação da identidade, o direito ao território, a condições para a busca da própria autonomia do ser e também à construção de uma visão própria do futuro. Em resposta à supressão das culturas locais, Escobar sugere a realização do comunal (Ibid.). Esta linha de pensamento fornece condições para a inventividade contínua comunitária e para o efetivo diálogo com seu entorno, além de considerar a articulação com outros atores sociais e tecnologias para o fortalecimento da própria comunidade, sendo portanto o design autônomo um impulso para a criação de novas formas emancipadas de viver.

A partir destes processos de emancipação, o educador brasileiro Paulo Freire (2015) propõe o reconhecimento da identidade cultural como um dos temas centrais para promover a emancipação do ser por meio da educação. Ao escrever sobre suas reflexões pedagógicas, sugere que é 
essencial que, além do reconhecimento, haja também respeito à identidade cultural socialmente construída na prática comunitária. Para atingir a autonomia é necessário o estímulo da capacidade criadora para que se possa responder às "inquietações indagadoras", partindo do senso comum, mas amparados no rigor científico para a compreensão de mundo. É fundamental pensar em formas de ampliar os conhecimentos e saberes reconhecidos como ciência, abrangendo suas abordagens, métodos e ferramentas, para um efetivo alargamento das visões de mundo, limitadas aos fatores hegemônicos.

Portanto, a autonomia do ser é obtida quando a busca por soluções deixa de ser postiça e, criticamente amparada, passa a encontrar correspondências em seu próprio tempo e território e em sua própria linguagem e identidade. Assim, acreditamos que o design relacional é um design decolonizado, que se apresenta como ferramenta de promoção da autonomia, considerando a identidade cultural local, mas de forma a estimular a cooperação entre os diversos atores sociais, apontando para um modo de viver colaborativo.

Como caminhos possíveis para práticas relacionais no design, elencamos três aspectos para orientar esta reflexão (ALMEIDA et al., 2017): (1) Democratizar os espaços de debate, criando lugares de compromisso com a pluralidade para a construção conjunta de propostas: nesses espaços, a cooperação entre distintos saberes, sejam eles populares, tradicionais, empíricos e/ou científicos, deve ser articulada de forma a permitir o trânsito entre os conhecimentos, rompendo com a hierarquia imposta pela tradição racionalista; (2) Praticar o design como ferramenta de resistência e emancipação e reconhecer ativamente o lugar de fala dos atores envolvidos, adotando uma postura capaz de romper com práticas institucionalizadas e paralisantes; (3) Propor processos vivos a partir de demandas locais e exercitar a reciprocidade e a constante troca entre as partes para promover corresponde^ncia entre os atores envolvidos. Estes aspectos elucidam as indagações percorridas neste artigo e seus possíveis caminhos para reflexão no que se refere à noção de relacional atribuída ao design.

\section{Considerações Finais}

Escrever este artigo partiu de nossa inquietação enquanto pesquisadoras do campo a respeito do que se entende por pensar e fazer design em nossas vivências, principalmente ao se relacionar com espaços informais, e sobre quais caminhos e trocas poderíamos percorrer a partir de nossas experiências. Nesse percurso, o termo relacional nos orientou na construção de nossas pesquisas. Nosso intuito aqui foi o de apresentar uma perspectiva: mais que categorizar uma abordagem para o design, a intenção foi a de 
multiplicar as maneiras de refletir sobre nossas ações e relações vivenciadas em campo. Acreditamos em perspectivas plurais e, portanto, que o conceito de relacional possa contribuir com outras pesquisas e endereçar novas práticas orientadas ao social, especialmente aquelas em contextos informais.

O design relacional, seja em pesquisas, na prática ou no ensino do design, visa sobretudo contribuir para a construção de uma sociedade mais justa, que não introduz conceitos totalizantes, mas outras formas de pensar e fazer design. A atenção dada com a mesma intensidade a todos os atores sociais, por meio da garantia do direito ao lugar de fala e da ampliação da escuta, assegura trocas mais justas. Acreditamos que essa postura relacional do design fomenta ideias colaborativas, fortalecendo a autonomia local por meio de soluções inatas e autóctones. Nosso intuito, ao escrever este artigo, foi o de ampliar e indagar como diferentes contextos, atores sociais e práticas podem ser considerados e inseridos de forma ativa dentro do campo do design. De forma não totalizante, pensamos que a noção de relacional está em constante construção, sugerindo perspectivas plurais e que coexistem em suas diferenças.

\section{Referências}

ACOSTA, A. O bem viver: uma oportunidade para imaginar outros mundos. São Paulo: Autonomia Literária, Elefante, 2016.

ALMEIDA, A. J. M.; MONTUORI, B. F.; ; NICOLETTI, V. M. . Manifesto: Por um design relacional. Seminário apresentado na conferência ."Entremeios: Tempos de Turbulência”. Centro Carioca de Design, Rio de Janeiro. 2017.

BUCHANAN, R. "Wicked Problems in Design Thinking”. In: Design Issues, Vol. 8, No. 2, (Spring, 1992),1992, p. 5-21.

DI SALVO, C. "Design and the Construction of Publics". In: Design Issues, 25, $n^{0} 1$, (Winter 2009), 2009, 48-63.

ESCOBAR, A. "Diseño para las transiciones". In: Etnografias Contemporáneas, v.3, $\mathrm{n}^{0}$ 4, 2017, p. 32-63.

La invención del tercer mundo: Construcción y desconstrucción del desarollo. Caracas: El pero y la rana, 2007.

Autonomía y diseño: la realización de lo comunal. Popayán: Universidad del Cauca Sello editorial, 2016. 
FREIRE, P. Pedagogia da autonomia: saberes necessários à prática educativa. Rio de Janeiro: Paz e Terra, 2015.

GAMMAN, L.; THORPE, A. "Design with society: why socially responsive design is good enough”. In: CoDesign 7 (3-4): 152-165, ano.

GATT, C.; INGOLD, T. "From description to correspondence: Anthropology in real time". In: GUNN, W. et al. Design Anthropology: theory and practice. London and New York: Bloomsbury, 139-158, 2013.

GUNN, W.; DONOVAN, J. (Eds.). Design and Anthropology. Surrey and Burlington: Ashgate, 2012.

GUNN, W. et al. Design Anthropology: theory and practice. London and New York: Bloomsbury, 2013.

HARAWAY, D. J. Staying with the Trouble: Making Kin in the Chthulucene. London: Duke University Press, 2016.

HARLAND, R. G.; SANTOS, M. C. L. "The ephemeral aesthetic of spontaneous design on the streets of Sao Paulo". In: Durling et al., (Eds). Undisciplined! Proceedings of the Design Research Society Conference 2008, Sheffield Hallam University, Sheffield, UK, 16th-19th July, 2008.

INGOLD, T. "From the Transmission of Representations to the Education of Attention”. In: H. Whitehouse (Ed.). The Debated Mind: Evolutionary Psychology Versus Ethnography, Oxford: Berg, 113-153, 2001.

"On human correspondence". In: Journal of the Royal Anthropological Institute, 23 (1), March 2017, 9-27. DOI: 10.1111/14679655.12541.

. "Trazendo as coisas de volta à vida: Emaranhados criativos num mundo de materiais”. In: Horizontes Antropológicos, Porto Alegre, ano 18, no 37, p. 25-44, jan./jun. 2012.

JANZER, C. L.; WEINSTEIN, L. S. Social Design and Neocolonialism. In: Design and Culture, 6(3), p. 327-343, 2014.

LATOUR, B. A Cautious Prometheus? A Few Steps Toward a Philosophy of Design (With Special Attention to Peter Sloterdijk). Keynote lecture for the 
Networks of Design meeting of the Design History Society, Falmouth, Cornwall, 2008. Available at <http://www.brsuno-latour.fr/ sites/default/files/112-DESIGN-CORNWALL-GB.pdf>.

LÉVI-STRAUSS, C. The savage mind. London, Weidenfeld and Nicolson, 1966.

LOSCHIAVO DOS SANTOS, M. C. "Spontaneous design, informal recycling and everyday life in postindustrial metropolis". In Pizzocaro, S.; Arruda, A.; de Moraes, D. (Eds), Design plus Research Conference, Politecnico di Milano: Milano, pp. 459-66, 2004.

MAGALHÃES, A.; LEITE, J. de S. (Ed). Encontros: Aloisio Magalhães. Rio de Janeiro: Beco do Azougue, 2014.

MAUSS, M. Sociologia e Antropologia. São Paulo: Ubu, 2017.

MAZÉ, R. "Our common future? Political questions for designing social innovation”. In: Design Research Society, 2014, 520-531.

MEHROTRA, R. "Working in Bombay: The City as Generator of Practice". In: Anytime, June, 1998, 64-69. Disponível em: http://www.rmaarchitects.com/essays/working-in-bombay.pdf

RANCIÈRE, J. O mestre ignorante: cinco lições sobre a emancipação intelectual. Belo Horizonte: Autêntica, 2002.

RITTEL, H.W.J.; WEBBER, M. M. Dilemmas in a general theory of planning. In: Policy Sciences, Vol. 4, N.4, 1973, p. 155-169.

SENNETT, R. Together: the rituals, pleasures \& politics of cooperation. London: Penguin Books, 2013.

SMITH, R. C.; VANGKILDE, K. T.; KJÆRSGAARD, M. G.; OTTO, T.; HALSE, J.; BINDER, T. Design Anthropological Futures. London; New York: Bloomsbury, 2016.

SPIVAK, G. C. Can the subaltern speak? Reflections on the history of an idea. New York: Columbia University Press, 2010.

STRATHERN, M. Partial Connections. Lanham, MD: Rowman and Littlefield, 1991. 
TUNSTALL, E. "Decolonizing Design Innovation: Design Anthropology, Critical Anthropology, and Indigenous Knowledge”. In: Gunn, W., Otto, T., Smith, R. C. (Eds). Design Anthropology: theory and practice. London and New York: Bloomsbury, 2013, 232-250.

VIVEIROS DE CASTRO, E. 2002. "O nativo relativo". In: Mana, 8 (1), Rio de Janeiro, 2002, 113-148. DOI: 10.1590/S0104-93132002000100005.

"Perspectival Anthropology and the Method of Controlled Equivocation”. In: Journal of the Society for the Anthropology of Lowland South America, Vol. 2, Iss. 1, Article 1, 2004.

WAGNER, R. A invenção da cultura. São Paulo: Cosac Naify, 2010. 


\section{Como citar}

ALMEIDA, Ana Julia Melo et al. Por práticas relacionais no design. Arcos Design. Rio de Janeiro: PPD ESDI - UERJ. Volume 12 Número 1 Julho 2019. pp. 5-24. Disponível em: [http://www.epublicacoes.uerj.br/index.php/arcosdesign]

DOI: $10.12957 /$ arcosdesign.2019.47521

\section{(C)(1) $(0 \bigcirc$}

A Revista Arcos Design está licenciada sob uma licença Creative Commons Atribuição - Não Comercial - Compartilha Igual 3.0 Não Adaptada. 